\title{
Critical Success Factors In the Implementation of Strategy by the Multinational Corporations in the Pharmaceutical Industry: An Empirical Investigation
}

\author{
Zachary Bolo Awino, PhD. \\ University of Nairobi Business School
}

\begin{abstract}
Strategy implementation is the key that opens doors to creatively align organizational strategy with its internal support systems that transforms analyzed and formulated strategies into action. An organization in the pharmaceutical business, which is a business that competes in the knowledge economy for discovering and commercializing therapeutic agents, must endeavour to continually develop strategies to protect its intellectual capital and improve performance. Despite this realisation the importance of strategy implementation, is still greatly overshadowed by a focus on the strategy formulation process. Literature available on strategy implementation is very scarce and especially in the pharmaceutical industry. This study, therefore, is poised to explore and determine the critical success factors for strategy implementation among Multinational corporations in the Kenyan pharmaceutical industry. The study was conducted in Kenya in 2014 as a census survey of twelve Multinational pharmaceutical corporations. Data for this survey was collected through the use of structured questionnaires, which were distributed to 36 respondents of which 32 responded an $89 \%$ respondent rate. This study was hinged on the dynamics capabilities theory, resource based view theory and the concept of competitive advantage. Data analysis was done using descriptive statistics and factor analysis to a large extent. Results indicate that critical success factors for strategy implementation include; Infrastructure factors; Clear and concise communication of the strategy to the staff, with a variance loading of(0.942)Resource set aside for new strategy,(0.871,variance loading),Planning, co-ordinating, monitoring and delegation of responsibilities for implementation of strategy,(0.970), Organisational structure that is supportive $(0.889)$.Time frame; Specified time frame allocated for strategy implementation(0.971), allocation for obstacles surfaced during implementation that were not envisioned beforehand, environmental factors also emerged as key to this process. For competitive advantage. People-product mix; Possession of detailed knowledge on customers' needs, tastes and preferences by employees, hiring and retraining top talent within the organization, continuous product improvement and innovations, Production of unique products for a specific target market, partnering with customers to produce highly customized products and strategic alliances with key stakeholders in the industry. These factors had implication on theory and practice since they were found to be universal.
\end{abstract}

Key words: CFSs, Strategy, Implementation, Pharmaceutical, Industry, MNC, Kenya

\section{BACKGROUND}

Strategy is defined as the direction and scope of an organization over long term, which achieves advantage for the organization through its configuration of resources within a 
changing environment to fulfil stakeholder expectation (Johnson and schools.2000). Michael Porter has defined strategy as "Creation of a unique and valued position involving a different set of activities. The company that is strategically positioned performs different activities from rivals or performs similar activities in different ways. An organization is considered efficient and operationally effective if it is characterized by coordination between objectives and strategies. There has to be integration of the parts into a complete structure. Strategy helps the organization to meet its uncertain situations with due diligence. Without strategy, an organization is like a ship without a rudder. It is like a tramp, which has no particular destination to go to.

Top and middle management of most organizations have had to grapple with ways of designing new and innovative strategies that will give their organizations a competitive edge to survive in their respective industries. To achieve success, a strategy must be translated into guidelines for daily activities for firm members, the strategy and firm must become one, that is, strategy must be reflected in the way the firm organizes its activities and in the firm's values, beliefs and tone (Pearce and Robinson, 1991).

Is has been reported that there is a very good understanding of the extent of strategic responses by the pharmaceutical companies in Nairobi to environmental changes (Khalif, 2012). The challenge however remains in the translation of these strategies into action plans that are actually implemented within their proposed time frame. The guiding principles in any strategic management process is the understanding of what changes are needed, how to implement and manage these changes, how to create a roadmap for sustaining improvements that lead to better performance (Morgan and Strong,2003).

To understand the critical success factors that contribute to successful strategy implementation, we must first gain an understanding of why strategies fail. There are mainly three reasons that lead to strategy failure that can be summarised as, company initiatives not aligned with the company strategy, Company processes not aligned with strategy and Employees and stakeholder failing to engage. For strategy to be implemented successfully every activity in an organization, apart from the very functional ones must be reviewed against its relevance to the new strategy being implemented. It bears no fruit to create a new strategy but continue to do the same old things.

A transformational strategy requires a transformation of the organizational structure. The structure of an organisation must allow strategy to cascade across and down the organisation in a way that meaningfully and efficiently delivers the strategy. Organisations that try and force a new strategy into an out-dated structure will find their strategy implementation eventually reaching a deadlock. One major reason why strategy execution fails is because the organisation does not get behind it. If staff and critical stakeholders in a particular organization do not understand the strategy and fail to engage, then the strategy has failed.

Strategy involves change: Change is difficult and human tendency is to resist it. So no matter how enlightened and inspiring your new strategic vision is, it will come up against hurdles and management must prepare the staff for these changes. An understanding of each of these hurdles and developing strategies to overcome them is critical. Strategic leaders must endeavour to bring on board influential employees, not just executive team members into the planning process. Not only will they contribute meaningfully to strategy, they will also be critical in ensuring the organisation engages with the strategy. Furthermore, listening across the organisation during strategy formulation is critical; some of the best ideas will come from within the organisation, not the executive team. An example would be 3M and its Post-It Notes. 
Communication: Every staff member must understands the strategic vision, the strategic themes and what their role will be in delivering the strategic vision. Communication of the strategy must be enriched through a combination of presentations, workshops, meetings, newsletters, intranets and updates. Strategy and performance updates should be continued throughout the year. It is also prudent for strategic management to engage the staff emotionally in the vision, a vision that they will want to invest and engage with would be a vision they believe in.

It is critical that all employees are aware of expectations. How are they expected to change, what and how are they expected to deliver, each individual must understand their functions within the strategy, the expected outcomes and how they will be measured. Lastly Strategies must be adaptable and flexible so they can respond to changes in both internal and external environments of a company. Strategy meetings should be held regularly throughout the year, where initiatives and direction are fully reviewed to check them against changes in external and competitive environments as well as internal environment for performance and strategic relevance. For strategy to succeed the whole organisation must engage with it, live and breathe it. It is on this understanding that this paper explores the contextual perspective of the pharmaceutical multinational corporations in Kenya as the basis in which CSFs of strategy implementation is done.

The United Nations definition of a multinational corporation is "an enterprise which owns or controls production or service facilities outside the country in which it is based". Thus a multinational company carries on business operations in two or more countries. Its headquarters are located in one country (home country) but its activities are spread over in other countries (host countries).Kenya's rapidly growing pharmaceutical and consumer health market is estimated to be worth a whooping $\$ 160$ million each year, with it's private health sector contributing approximately $13 \%$ to the GDP, this however, has largely remained unchanged since 1995(KPPB, 2007). Out of this, Pharmaceutical industries account for $10.3 \%$ in its contribution to the GDP. The growth rate is projected to reach 5.4 per cent this year (2014), up from 2.5 per cent recorded in 2009.

The Kenyan pharmaceutical industry consists of a host of players who include the research based multinational companies, local manufacturers mainly of generic medicines, importers of branded and non-branded generic medicines and counterfeits. There are a total of 42 companies listed as local manufacturers of which only one (GlaxoSmithKline) is a multinational company, 15 others are listed as institutional/facility based (UNIDO, 2010) and a further twelve as research-based multinational pharmaceutical (MNPCs) companies in Kenya, of these; seven have a regional offices in the country while five others have appointed agents. The remaining players in this market include distributors who also serve as agents of generic manufacturing companies.

Multinational pharmaceutical companies (MNPCs) rely heavily on the research and development model that is based on the innovation of novel treatments that, once patented and marketed successfully drive the company's large revenues and resultant growth through its parent company and subsequently its subsidiaries throughout the world. According to the Pharmaceutical Executive report, Exec top 50 which provides an annual ranking of the world's pharmaceutical companies based on their prescription drugs. Pfizer Laboratories retained its slot as the leading (MNPC) in terms of revenue based on the 2013 exchange rates. Other companies in the top ten positions include; Novartis, Merck, Sanofi Aventis, Hoffman le Roche, GlaxoSmithKline at sixth position, Astra Zeneca, Abbot and Eli-lily, (Pharmaceutical Executive, 
2014 report based on 2013 revenues). It is important to note that these top ten MNPCs in the world also conduct marketing and sales activities in Kenya's neighbouring countries using Kenya as their regional base.

\section{LITERATURE REVIEW}

Strategy implementation or otherwise known as strategy execution is easily the most complicated and time-consuming part of strategic management (Thompson \& Strickland, 2003). In contrast, strategy formulation is primarily an intellectual, creative act involving analysis and synthesis. Implementation on the other hand is a hands-on operation and actionoriented human behavioural activity that call for executive leadership and key managerial skills. Strategy implementing functions consist of finding out what it will take to make the strategy work and to reach the targeted performance on schedule. It is action driven administrative task that cuts across many internal functions of an organization. (Thompson and Strickland, 1999). Once strategies have been developed, they need to be implemented. Unless they are successfully implemented an organisation cannot obtain desired results. Pearce and Robinson (2002).

Barriers to strategy implementation have been identified as; competing activities that destruct attention from implementing the decision; changes in employees responsibilities not clearly defined; key formulator of the strategic decision not playing an active role in implementation, problems requiring top management involvement not being communicated early enough, overall goals not sufficiently defined, and understood by employees; uncontrollable factors in the external environment, surfacing of major problems not identified during formulation, advocates and supporters of the strategic decisions leaving the organization during implementation and implementation taking more time than earlier allocated. Al-Ghamdi (1998).

Many researchers have discussed the metrics coherent with strategy formulation and implementation principles. One of the most mentioned concepts is the balanced scorecard by Kaplan and Norton in the 1990s. This concept proposes that every firm should adopt a specific set of key performance indicators. These indicators measure whether driving activities led to the expected results. Performance indicators must follow critical implementation factors what include: 1. Measuring necessary time for strategy execution, 2. Organizational structure adequacy, 3. Organizational culture, 4. Resource planning and 5. Strategic Leadership.

Organizations must ensure that every strategy-related action has a due date. This can be achieved by building into the strategic plan, milestones that must be achieved within a specific time frame. Alternatively, organizations may opt to schedule sixty-day strategy reviews by senior management. These will provide an opportunity to take another look at the original plan, determine whether strategic objectives are being met, and agree on new action steps as necessary. Managers may let the due date slip, but should not let it go away. This will hold each and every stake holder accountable for the deadline of their actions in strategy execution.

A transformational strategy requires a transformation of the organizational structure. The structure of an organisation must allow strategy to cascade across and down the organisation in a way that meaningfully and efficiently delivers the strategy. Organisations that try and force a new strategy into an out-dated structure will find their strategy implementation eventually reaching a deadlock.

Weihrich and Koontz (1993) look at culture as the general pattern of behaviour, share beliefs and values that members have in common. Culture can be inferred from what people do and 
think within an organization setting. It involves the learning and transmitting of knowledge, belief and patterns of behaviour over time. This implies that organizational culture sets the tone for the company to establish rules on how people should behave and in essence how successfully strategy will be implemented. A strategy-supportive corporate culture enhances the ease in execution of strategy; it promotes an environment where employees are encouraged to work hard toward the accomplishment of the strategy.

Organisational performance should also be closely aligned to strategy. Performance measures should be placed against strategic goals across the organisation and each division and staff member. All staff will therefore have job functions that will impact on strategy. Strategic management must ensure employees are aware of their role and influence on strategy delivery and performance. Norton and Kaplan in their book 'The Execution Premium' recommend cross functional strategic initiatives be allocated specific budget alongside capital and operating budgets. This protects strategic expenditure from being re-allocated to short-term requirements of operating budgets whilst subjecting strategic initiatives to a rigorous review.

Strategy involves change. Change is difficult and human tendency is to resist it. So no matter how enlightened and inspiring the new strategic vision maybe, it will come up against hurdles and management must prepare the staff for these changes. Tipping Point Leadership theory outlines four key hurdles that executives must overcome to achieve execution. Those hurdles are cognitive, resource, motivation and political hurdles. An understanding of each of these hurdles and developing strategies to overcome them is critical. Strategic leaders must endeavour to bring on board influential employees, not just executive team members into the planning process. Not only will they contribute meaningfully to strategy, they will also be critical in ensuring the organisation engages with the strategy and ensure its successful implementation.

For factors external to the organization affecting strategy implementation, it is important to set up a detailed assessment of their occurrence and impact. It is also important to apply quantitative and qualitative indicators.The factors above may not be exhaustive as critical success factors in strategy implementation may be case dependent, but as companies look for ways to implement corporate-level strategies, this offers a checklist for the process.

\section{Methods}

\section{METHODS AND RESULTS}

A Census survey was employed in this study to gain insights on how strategy is currently implemented among the top Multinational Pharmaceutical Corporations in Kenya. This survey helped to determine what management of these organizations consider as the critical success factors for implementation of their strategies.

This offered convenience of administration and therefore favours capturing all the relevant data to enable comparison of the critical factors in strategy implementation for the Multinational pharmaceutical Corporations in Kenya. A census study enhances wide representation of the current state and a definite answer to the research questions (Mugenda \& Mugenda 2003).

The top twelve multinational pharmaceutical companies based on 2013 global revenue that have subsidiaries/regional offices in Kenya constituted the population of the study under which the findings of this study was based. These corporations form the top Multinational Pharmaceutical companies in the world, according to The Pharma exec's Report, on the top 
twelve Multinational companies based on 2013 Global Revenue. This provides a good representation of the study subject to help fill the research gaps.

The population of the study presents a manageable and accessible population since these corporations are all headquartered in Nairobi where the study was conducted. A population is a well-defined or set of people, services, elements, and events, group of things or households that are being investigated. (Ngechu, 2004).

Data was collected through the use of a structured questionnaire. The questionnaires contained close ended questions and were administered through a drop and pick later method. The respondents were; Chief Executive officers or their equivalents, Business development Managers, Product Mangers and Sales Managers responsible for strategy implementation in the Multinational Pharmaceutical companies under study.

The data collected was then analysed using the, descriptive statistics involving use of mean, mode and median Factor analysis was also employed in this study in description of the wide variety of variables, using a few factors. This helped to analyze the aspects of independent variables which may have been correlated with the dependent variables; it was also used to reduce many factors into a manageable number-for ease of data presentation and interpretation

\section{Results}

Data collected from the 32 questionnaires presented a host of factors that are critical to each individual organization for strategy implementation. Before extraction, there were as many factors as the number of variables in the data, as expressed in the tables to follow. Factor analysis was used to identify the major components that are critical for strategy implementation. From factor analysis various parameters were used to reduce the data to a manageable size. These parameters included: Eigen values, percentage variances, Extraction Sums of Squared Loadings and Rotation Sums of Squared Loadings, these are all expressed in the rotation matrix tables from each section of the questionnaire.

Table 1 Rotation matrix for critical success factor for strategy implementation

\begin{tabular}{|c|c|c|c|c|c|c|c|c|c|}
\hline \multirow[t]{2}{*}{ 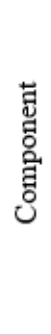 } & $\begin{array}{l}\text { Initial } \\
\text { Eigenvalu } \\
\mathrm{e}\end{array}$ & & & 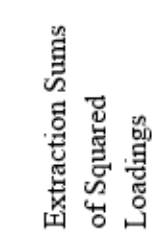 & & & 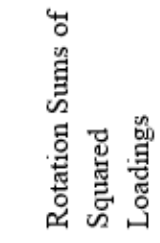 & & \\
\hline & Total & $\begin{array}{l}\% \text { of } \\
\text { Variance }\end{array}$ & $\begin{array}{l}\text { Cumulative } \\
\%\end{array}$ & Total & $\begin{array}{l}\% \text { of } \\
\text { Variance }\end{array}$ & $\begin{array}{l}\text { Cumulative } \\
\%\end{array}$ & Total & $\begin{array}{l}\% \text { of } \\
\text { Variance }\end{array}$ & $\begin{array}{l}\text { Cumulative } \\
\%\end{array}$ \\
\hline 1 & 4.551 & 50.570 & 50.570 & 4.551 & 50.570 & 50.570 & 3.616 & 40.172 & 40.172 \\
\hline 2 & 1.660 & 18.446 & 69.017 & 1.660 & 18.446 & 69.017 & 1.173 & 13.037 & 53.210 \\
\hline 3 & 1.068 & 11.863 & 80.880 & 1.068 & 11.863 & 80.880 & 1.091 & 12.123 & 65.333 \\
\hline 4 & .900 & 10.004 & 90.884 & .900 & 10.004 & 90.884 & 1.069 & 11.875 & 77.208 \\
\hline 5 & .334 & 3.707 & 94.590 & .334 & 3.707 & 94.590 & .875 & 9.718 & 86.925 \\
\hline 6 & .223 & 2.476 & 97.067 & .223 & 2.476 & 97.067 & .864 & 9.596 & 96.522 \\
\hline 7 & .169 & 1.879 & 98.946 & .169 & 1.879 & 98.946 & .193 & 2.143 & 98.664 \\
\hline 8 & .090 & 1.001 & 99.947 & .090 & 1.001 & 99.947 & .115 & 1.281 & 99.945 \\
\hline 9 & .005 & .053 & 100.000 & .005 & .053 & 100.000 & .005 & .055 & 100.000 \\
\hline
\end{tabular}

Table 2 show the factor loading values after rotation. Rotation has the effect of optimizing the factor structure and one consequence for these data is that the relative importance of two factors is equalized. Loadings highlighted in bold correlate and load onto one component. 
In this case Component one represents: Clear and concise communication of the strategy to the staff, Resources set aside for new strategy, Planning, co-ordinating, monitoring and delegation of responsibilities for implementation of strategy and Organisational structure that is supportive. Second component; Obstacles surfaced during implementation that were not envisioned before hand and Third component; specified time frame allocated for strategy implementation.

Table 2: Loading values for critical success factors for strategy Implementation.

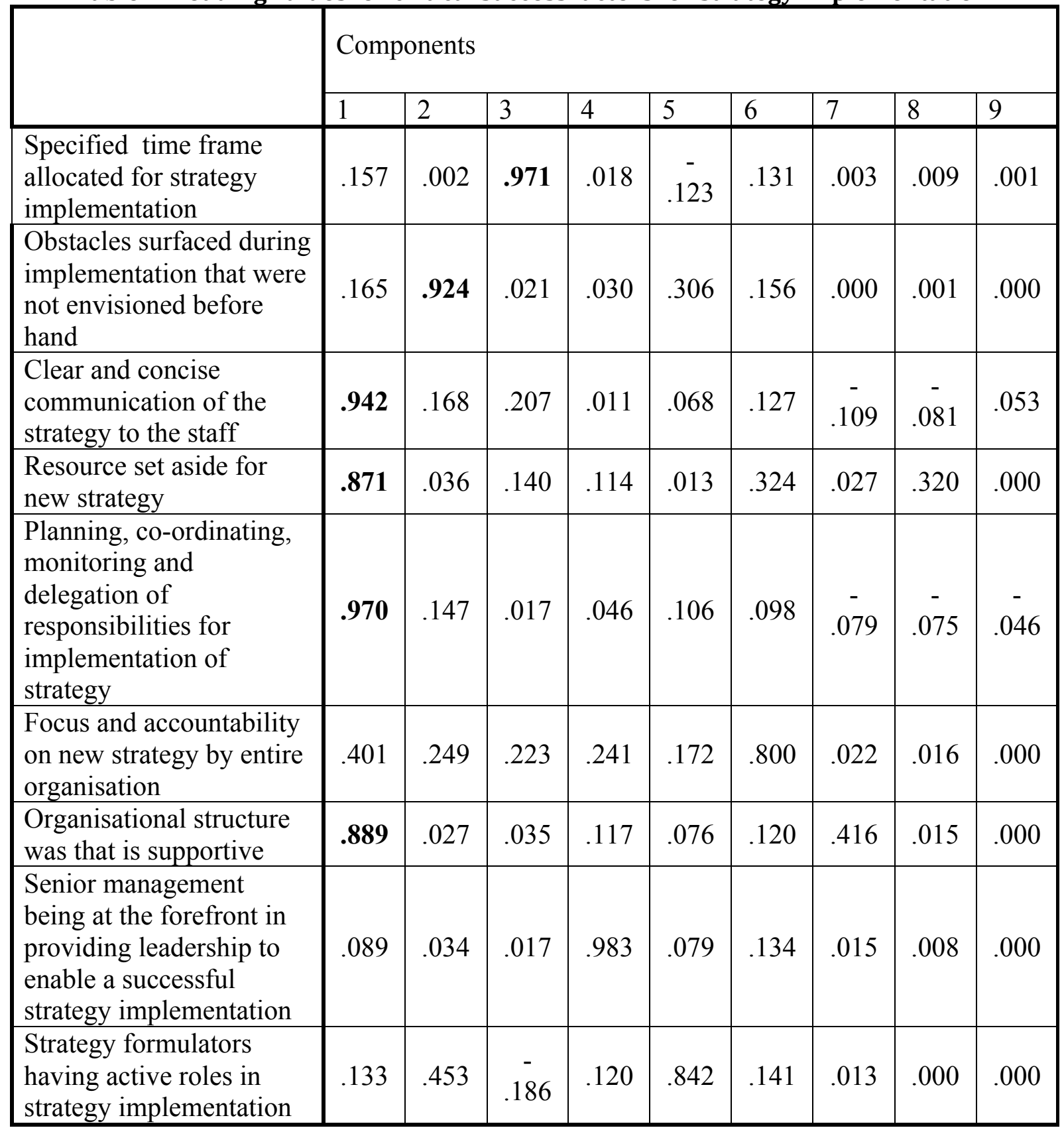

The first three Initial Eigen values before extraction were the highest as illustrated in table 3 below.

The percentage of variance column illustrates the total variance accounted for by the individual factors where as the cumulative percentage of variance shows total variance accounted for by current and all preceding factor variances totalling up to $100 \%$.The extraction sums of squared loadings column correspond to the number of factors retained for extraction 
this analysis pre- set three factors for analysis and those are the first three in this column. Finally the rotation sums of square loadings illustrates the distribution of the variance among the factors after rotation, the total amount of variance accounted for is redistributed over the extracted factors.

Table 3: Eigen values for factors with high correlations in Localising Global Strategies

\begin{tabular}{|c|c|c|c|c|c|c|c|c|c|}
\hline \multirow[t]{2}{*}{$\begin{array}{l}\text { 䓂 } \\
\text { 起 } \\
\text { ठ }\end{array}$} & $\begin{array}{l}\text { Initial } \\
\text { Eigenvalues }\end{array}$ & & & 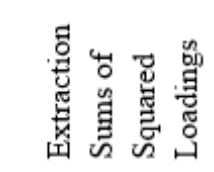 & & & 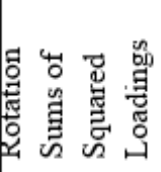 & & \\
\hline & Total & $\begin{array}{l}\% \text { of } \\
\text { Variance }\end{array}$ & $\begin{array}{l}\text { Cumulative } \\
\%\end{array}$ & Total & $\begin{array}{l}\% \text { of } \\
\text { Variance }\end{array}$ & $\begin{array}{l}\text { Cumulative } \\
\%\end{array}$ & Total & $\begin{array}{l}\% \text { of } \\
\text { Variance }\end{array}$ & $\begin{array}{l}\text { Cumulative } \\
\%\end{array}$ \\
\hline 1 & 2.143 & 30.612 & 30.612 & 2.143 & 30.612 & 30.612 & 1.005 & 14.363 & 14.363 \\
\hline 2 & 1.368 & 19.549 & 50.161 & 1.368 & 19.549 & 50.161 & 1.005 & 14.360 & 28.723 \\
\hline 3 & 1.083 & 15.469 & 65.629 & 1.083 & 15.469 & 65.629 & 1.005 & 14.351 & 43.074 \\
\hline 4 & .860 & 12.279 & 77.909 & .860 & 12.279 & 77.909 & 1.000 & 14.284 & 57.358 \\
\hline 5 & .623 & 8.894 & 86.803 & .623 & 8.894 & 86.803 & .997 & 14.240 & 71.598 \\
\hline \multirow{2}{*}{$\begin{array}{l}6 \\
7\end{array}$} & .487 & 6.961 & 93.764 & .487 & 6.961 & 93.764 & .996 & 14.229 & 85.827 \\
\hline & .437 & 6.236 & 100.000 & .437 & 6.236 & 100.000 & .992 & 14.173 & 100.000 \\
\hline
\end{tabular}

After the initial eigen values, the content of questions were then loaded onto the same components to try to identify common themes (see table below)there is one variable for each of the factors 1, 2 and factor 3 highlighted in bold).This clearly illustrates the main factors involved in localising global strategies to suit local challenges and opportunities to strategy implementation; Modify global strategy to suit local environment, with a loading of (0.972),Proactively seek good relationship with the government(0.984) and Local training to enhance technological competence with a factor loading after extraction of $(0.981)$ as demonstrated in table 4 below.

Table 4: Extraction of critical success factors in localising global strategies

\begin{tabular}{|c|c|c|c|c|c|c|c|}
\hline \multirow{2}{*}{ Variables } & \multicolumn{7}{|c|}{ Component } \\
\hline & 1 & 2 & 3 & 4 & 5 & 6 & 7 \\
\hline $\begin{array}{l}\text { Modify global strategy to suit local } \\
\text { environment }\end{array}$ & .972 & .043 & .073 & $\begin{array}{c}- \\
.085\end{array}$ & $\begin{array}{c}- \\
.039\end{array}$ & .095 & .172 \\
\hline $\begin{array}{l}\text { Harmonize accounting practices to } \\
\text { reduce financial risks }\end{array}$ & .183 & .141 & -.026 & .107 & .134 & .093 & .953 \\
\hline $\begin{array}{l}\text { Merge East Africa markets to } \\
\text { enlarge market }\end{array}$ & -.041 & .060 & -.011 & .244 & .948 & .133 & .134 \\
\hline $\begin{array}{l}\text { Proactively seek good relationship } \\
\text { with the government }\end{array}$ & .042 & .984 & -.067 & .035 & .054 & .072 & .129 \\
\hline $\begin{array}{l}\text { Develop differentiated distribution } \\
\text { channels across East Africa markets }\end{array}$ & -.089 & .038 & -.063 & .952 & .241 & .105 & .106 \\
\hline $\begin{array}{l}\text { Working together with Kenyan } \\
\text { government for infrastructure } \\
\text { development }\end{array}$ & .099 & .077 & -.168 & .104 & .130 & .959 & .092 \\
\hline $\begin{array}{l}\text { Local training to enhance } \\
\text { technological competence }\end{array}$ & .072 & -.068 & .981 & .057 & $\begin{array}{c}- \\
.011\end{array}$ & -.157 & $\begin{array}{c}- \\
.024\end{array}$ \\
\hline
\end{tabular}

Factor analysis on data collected for response strategies for competitive advantage, revealed three high initial Eigen values as shown in table 13 below. These three components had an 
Eigen value of more that 1.0.This showed that these factors had some variations that were thereafter used to extract some common themes. The table below gives a comprehensive overview of the percentage variance, extraction sums of squared loadings and cumulative percentages for factors that respondents indicated as response strategies for competitive advantage.

Table 5: Extraction of factors for response strategies for competitive Advantage

\begin{tabular}{|c|c|c|c|c|c|c|c|c|c|}
\hline 高 & $\begin{array}{l}\text { Initial } \\
\text { Eigenvalues }\end{array}$ & & & 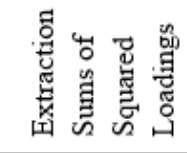 & & & 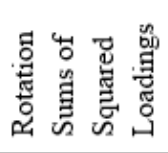 & & \\
\hline & Total & $\begin{array}{l}\% \text { of } \\
\text { Variance }\end{array}$ & $\begin{array}{l}\text { Cumulative } \\
\%\end{array}$ & Total & $\begin{array}{l}\% \text { of } \\
\text { Variance }\end{array}$ & $\begin{array}{l}\text { Cumulative } \\
\%\end{array}$ & Total & $\begin{array}{l}\% \text { of } \\
\text { Variance }\end{array}$ & $\begin{array}{l}\text { Cumulative } \\
\%\end{array}$ \\
\hline 1 & 3.896 & 43.287 & 43.287 & 3.896 & 43.287 & 43.287 & 2.643 & 29.371 & 29.371 \\
\hline 2 & 1.547 & 17.186 & 60.473 & 1.547 & 17.186 & 60.473 & 1.065 & 11.833 & 41.205 \\
\hline 3 & 1.487 & 16.519 & 76.992 & 1.487 & 16.519 & 76.992 & 1.050 & 11.667 & 52.872 \\
\hline 4 & .650 & 7.221 & 84.213 & .650 & 7.221 & 84.213 & 1.049 & 11.660 & 64.532 \\
\hline 5 & .530 & 5.884 & 90.097 & .530 & 5.884 & 90.097 & 1.036 & 11.515 & 76.047 \\
\hline 6 & .392 & 4.357 & 94.455 & .392 & 4.357 & 94.455 & 1.024 & 11.374 & 87.421 \\
\hline 7 & .260 & 2.894 & 97.349 & .260 & 2.894 & 97.349 & .546 & 6.071 & 93.493 \\
\hline 8 & .178 & 1.976 & 99.325 & .178 & 1.976 & 99.325 & .518 & 5.754 & 99.247 \\
\hline 9 & .061 & .675 & 100.000 & .061 & .675 & 100.000 & .068 & .753 & 100.000 \\
\hline
\end{tabular}

Table 6: Critical factors in response strategies for competitive advantage

\begin{tabular}{|l|l|l|l|l|l|l|l|l|l|}
\hline \multirow{2}{*}{ Variables } & \multicolumn{6}{|l}{ Components } \\
\cline { 2 - 10 } & 1 & 2 & 3 & 4 & 5 & 6 & 7 & 8 & 9 \\
\hline $\begin{array}{l}\text { Production of standardized } \\
\text { products at very low costs for } \\
\text { price sensitivity }\end{array}$ & .122 & -.030 & -.014 & .958 & .181 & .171 & -.062 & .012 & .003 \\
\hline $\begin{array}{l}\text { Reduction of operating expenses } \\
\text { to maximize on revenues }\end{array}$ & .177 & -.155 & .016 & .172 & -.016 & .955 & .025 & .051 & .000 \\
\hline $\begin{array}{l}\text { Strategic alliances with other key } \\
\text { stakeholders in the industry }\end{array}$ & .356 & .092 & .921 & -.017 & .017 & .012 & .088 & .087 & .002 \\
\hline $\begin{array}{l}\text { Possession of detailed knowledge } \\
\text { on customers' needs, tastes and } \\
\text { preferences by our employees }\end{array}$ & $\mathbf{. 8 9 0}$ & .136 & .181 & .200 & -.067 & .123 & .180 & .162 & .194 \\
\hline $\begin{array}{l}\text { Hiring and retraining top talent } \\
\text { Partnering with customers to } \\
\text { produce highly customized } \\
\text { products }\end{array}$ & .911 & -.002 & .304 & .068 & -.073 & .160 & .074 & .079 & -.174 \\
\hline $\begin{array}{l}\text { Continuous product improvement } \\
\text { and innovations }\end{array}$ & .115 &. $\mathbf{9 5 6}$ & .082 & -.031 & .173 & -.158 & .037 & .097 & .005 \\
\hline $\begin{array}{l}\text { Selling of products at lower } \\
\text { prices than competitors }\end{array}$ & -.124 & .171 & .012 & .181 & .956 & -.016 & -.084 & -.046 & .000 \\
\hline $\begin{array}{l}\text { Production of unique products for } \\
\text { a specific target market }\end{array}$ & $\mathbf{. 6 3 8}$ & .253 & .190 & .027 & -.108 & .120 & .116 & .672 & .004 \\
\hline
\end{tabular}

This data was then collated to show which specific factors show common themes and answer the research objective of what the critical success factors for strategy implementation among Multinational pharmaceutical cooporation are. Table 7 below clearly enlist the most critical 
success factors for strategy implementation in totality taking into account all the aspects of; localising global strategies and response strategies for competitive advantage according to data collected from the entire population of respondents.

Table 7: Ranking for components in Critical success factors for strategy Implementation

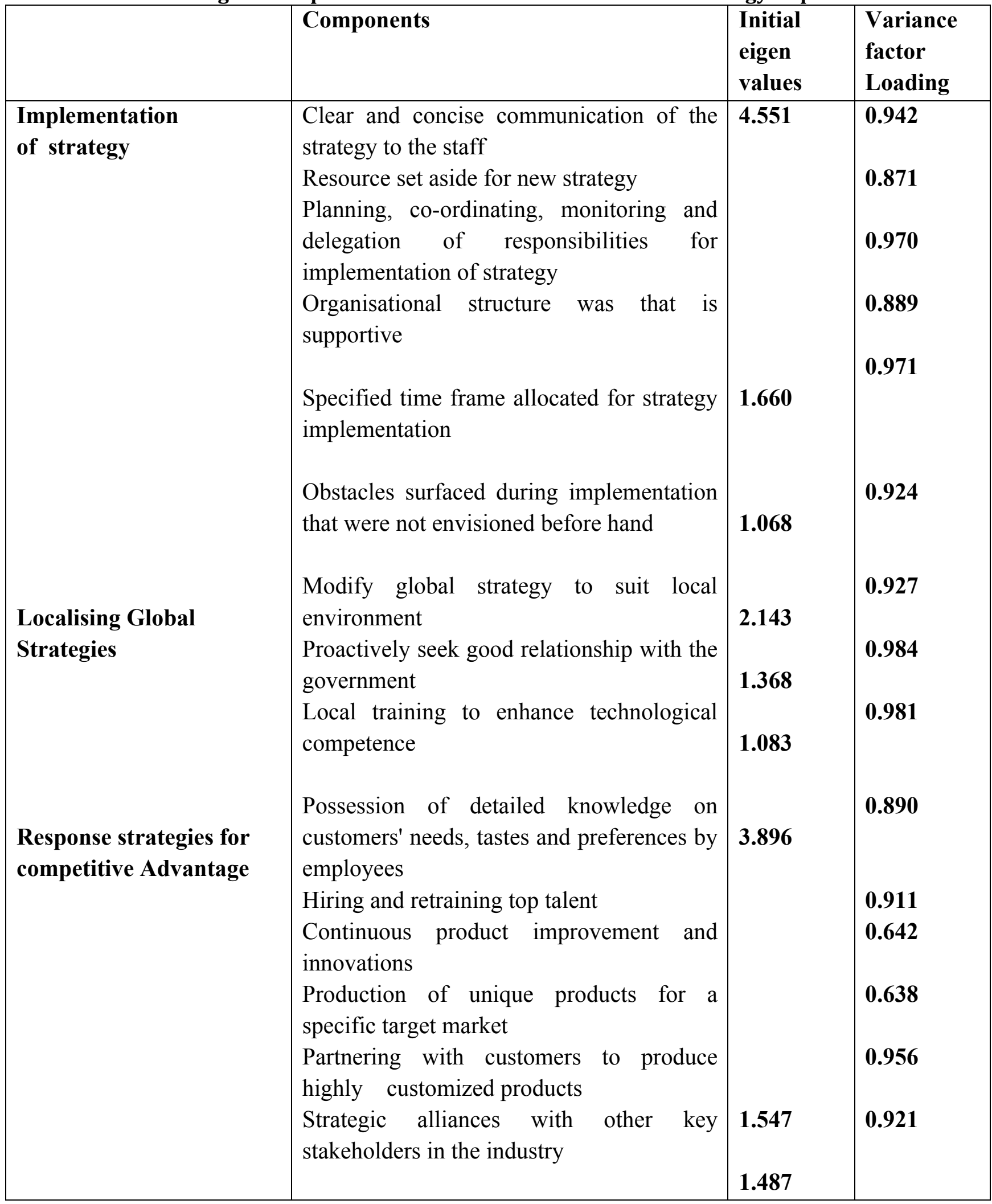

In summary ,it is evidenced by the data collected that the critical success factors for strategy implementation for Multinational pharmaceutical corporations in the Kenyan Pharmaceutical 
industry include and are limited to Management of these organization ensuring that there is a very Clear and concise communication of the strategy to the staff this factor had a factor loading of (0.942) and is highly correlated to Resources set aside for new strategies (0.871).These two very important factors are also closely correlated to Planning, co-ordinating, monitoring and delegation of responsibilities for implementation of strategy (0.970) and Organisational structure was that is supportive (0.889).These factors all load onto one component. These four factors a high correlation to one another and can therefore form one "invisible" factor and through factor analysis have been reduced to one overall factor (component) to answer in part the research objective of critical success factors to strategy implementation.

The second component that emerged as critical was Specified time frame allocated for strategy implementation with a loading of (0.971). Timelines are therefore very critical when it comes to successful strategy implementation. The third component with a loading of $(0.924)$ after factor extraction was consideration of Obstacles that may surface during implementation that had not envisioned beforehand.

A large number of the Multinational corporations operating in the Kenyan Pharmaceutical industry indicate from the responses that they have had to localise their global strategies for successful implementation. In this respect localisation of global strategy was mainly through modification of global strategy to suit local environment, with a loading of $(0.927)$, as the first key component. Multinational Pharmaceutical corporations proactively seeking good relationship with the government $(0.984)$ as the second component and Local training to enhance technological competence (0.981) as the third component. Analysis was able to show the factors that were highly correlated and highlight them as the key themes in line with the research objective.

These organizations have all put in place response strategies to maintain competitive advantage and factor analysis was able to identify the major components as; Possession of detailed knowledge on customers' needs, tastes and preferences by their employees, hiring and retraining top talent, continuous product improvement and innovations and production of unique products for a specific target market which loaded onto one component. Partnering with customers to produce highly customized products was identified as a second component and Strategic alliances with other key stakeholders in the industry as the third.

\section{DISCUSSION}

It is evident that after a thorough analysis of this data, nine distinct factors emerge as the most important when it comes to strategy implementation among Multinational Pharmaceutical corporations operating in the Kenyan industry from the huge amount of factors collated from this research as critical success factors to strategy implementation. One group of factors was; Clear and concise communication of strategy to staff. The role of managers in an organization is significant for effective people management and effective communication towards effective strategy implementation (Aaltonen and Ikavalko 2002).Resources set aside for strategy implementation, Planning, co-ordinating, monitoring and delegation of responsibilities for implementation of strategy and Organisational structure that is supportive. These factors can then be given one general title or name as they load onto one component showing that they form one theme and labelled as; Infrastructural issues in relation to this study.

Another distinct factor critical for strategy implementation success that has been demonstrated is Allowance for un-envisioned obstacles; putting into consideration Obstacles 
that may surface during implementation that were not necessarily envisioned beforehand. Successful implementation in part involves preventing implementation problems from occurring in the first place (Alexander, 1985).Affirms this point.Time frame; specified time frame allocated for strategy implementation was also demonstrated from data to be critical in pursuit for strategy implementation success.

Multinational organizations operating outside their home countries have had to consider, global strategy modification for competitive advantage, data suggest that MNC's operating in Kenyan pharmaceutical industry have at one point or another modified their global strategies to adapt to their local environments, this has been demonstrated by the fact that this factor accounted for $14 \%$ correlation after extraction by factor analysis showing significance by loading highly onto one component.

Multinational Pharmaceutical corporations have also had to proactively seek good relationship with the local government in implementation of their strategies; this has been demonstrated to be a factor critical for implementation of strategies among companies in the pharmaceutical industry. Another factor of importance is Training; Local training of staff operating in these environments will enhance their technological competence for competitive advantage.

The pharmaceutical environment is a very competitive one, 97\%of the population of respondents indicated that Multinational pharmaceutical corporations consider competition a significant factor to consider when looking at ways to attain a competitive edge in the industry. MNPC's in the Kenyan pharmaceutical industry have taken deliberate measures to remain competitive in their industry, which include; People-product mix, that involve the organizations ensuring that their employees posses detailed knowledge of customers' needs, tastes and preferences, Hiring and retraining top talent and Production of unique products for specific target markets.

Data from this survey has also shown that Strategic alliances with key stakeholders in the industry is key to attaining competitive advantage e.g. the strategic alliance between GSK and Dr Reddys pharmaceuticals from India, where Gsk has rights to market some of Dr Reddy's generic products.

\section{CONCLUSION}

Based on the results of the descriptive and factor analysis, it can be concluded that the target respondents from the participating organizations constitute comprehensive representation that allows for drawing of specific and concise conclusions on strategy implementation in the pharmaceutical industry and especially among Multinational Pharmaceutical companies. Due to globalization and increasing competition from manufacturers of generic drugs in the pharmaceuticals industry Multinational pharmaceutical cooperation operating in the Kenyan market have had to relook their strategies and how they are implemented.

The data presented in this research study indicate that critical success factors for strategy implementation such as infrastructure issues that include; resources being set aside for strategies, management being at the forefront in communicating the new strategy and supportive organizational are some of the bare minimum requirements for successful strategy implementation. These issues must therefore be implemented in organizations not only in the pharmaceutical industry but any organizations that harbour any intentions of being successful in its industry. 
Management of multinational Pharmaceutical corporations organizations must endeavour to put in place suitable formulas for hiring and retaining top talent for example offering attractive compensation packages that would allow employee motivation, and revolution of human resource departments through embracing of policies that would enable individual employee's growth and development as well comprehensive localised training for their staff, suited for their specific and unique environment, would serve to enhance staff competence and in turn enhance their retention in these organizations.

(Nyaboke,2012) in her study that looked at sustainable competitive advantage among MNC's in the pharmaceutical industry, confirms this in her conclusion that possession of superior skills and especially recruiting the best talent in the market and training would propel an organization to achieve competitive advantage. Galbraith (1987) presents keen perspective to explain that an organizational capability is created when people, structure, rewards, and processes are created and combined to support task performance, and that the company must put into place organizational structures, management process, rewards, and incentives, and the human resource practices that support the task performance. The Galbraith (1994) Star Model of organizational capability does address essential requirements for defining and creating a supportive system for task performance.

Possession of detailed knowledge on customers' needs, tastes and preferences by employees, Continuous product improvement and innovations and Production of unique products for a specific target market are key strategies for competitive advantage. These factors confirm the dynamics capabilities theory that a firm has ability to renew its internal resources in line with changes in its environment for its own advantage. Turbulent environments may change the significance of resources for organization (Penrose 1959).

Taking environmental factors into consideration for example, inflation rates that affect consumption of products, Since change has become an enduring feature of organizational life (Rose and Lawtone, 1999), today's managers have to face the challenges posed by the environment hence embrace the ensuing strategic responses.

Strategic alliances with other key stakeholders in the industry as suggested in by the data in this research study, will help these MNPC's to better implement their strategies for greater revenue generation and profit maximization.(Chesbrough,2006) in his study of the pharmaceutical companies concluded that those companies that are unable to sufficiently undertake development within their organizations, align themselves to exploit the knowledge of other firms to get ahead. This is clearly demonstrated in the Kenyan pharmaceutical industry through their strategic alliances, examples are Glaxo smithkline and Dr Reddy's, Norvatis and Sandoz pharmaceuticals.

\section{References}

Al-Ghamdi, S.M. (1998). Obstacles to Successful Implementation of Strategic Decision the British Experience; European Business Review, 98 (6), 6-11.

Global UNIDO Project; strengthening the local production of essential generic drugs in least developed and developing countries, Vienna 2010.

Gassmann. O. Reepmeyer. G, Von Zedtwitz, M (2004b) Leading Pharmaceutical Innovation Trends and Drivers for Growth in the Pharmaceutical Industry, Berlin: Springer.

Gorsuch, R. L. (1983), NJ: Lawrence Erlbaum Associates. Factor analysis (2nd Ed.). Hillsdale,

Ireri, K.M, (2013)," Factors Affecting Strategy Implementation Process; The Pharmaceutical Distributors within Nairobi County" Unpublished MBA Research Project University of Nairobi. 
Johnson, G., Scholes, K. and Whittington, R. (2005) Exploring corporate strategy: text and cases, (7th Edition), Prentice Hall.

Kosiom, C.J (2013)," The challenges of Implementing Global Strategies by Multinational Organizations in Kenya”, Unpublished MBA Research Project University Nairobi.

Li, Y, Guohui, S. Eppler M.J. (2008) Making Strategy Work: A Literature Review Factors influencing strategy implementation. ICA working paper.

Mbithi, M.N, (2011)," Strategy implementation at Nakumatt holdings Limited,

Kenya", Unpublished MBA Research Project University of Nairobi.

Mugenda O.M \& Mugenda A.G (2003), Research Methods: Quantitative and qualitative appproch ACTS Press Nairobi, Kenya.

Nyaboke, R.0, (2012)," Strategies applied by Multinational Pharmaceutical MBA Corporations in Kenya to attainable sustainable Competitive Advantage"Unpublished Research Project University of Nairobi

Porter, M, (1990), The Competitive Advantage of Nations, THE FREE PRESS, A Division McMillan, Inc., New York, 1990, p xii.

Porter, M. E. (1985). Competitive Advantage; Creating and Sustaining Superior Performance. New York: The Free Press.

Porter, M. (1980), Competitive Strategy, New York, Free Press Pearce, J.A \& Robinson, R.B., (2010) Strategic Management: Formulation, Implementation and Control, (12th Intl Edition).

Peteraf, M. (1993).The cornerstones of competitive advantage: A resource-based view Strategic Management Journal, 14: 179-191.

Prahalad, C. K., \& Hamel, G. (1990). the core competence of the corporation.

Harvard.Business Review, 68, 3: 79-91.

Quinn. J. B. (1992). Intelligent enterprise. New York, NY: Free Press.

Rajan. V.P \& Jayachandran, S., (1999). Marketing Strategy: An Assessment of the State of the Filed and Outlook. Journal of the Academy of Marketing Science 27 (2): 120-143.

Sapienza, A. M. (1995).Managing scientists: Leadership strategies in research and development. New York, NY: Wiley-Liss, Inc

Saloner, G., Shepard, A., \& Podolny J, (2001).Strategic Management, New York: John Wiley \& Sons.

Slater, S F, and Naver, J. C. (1995). Market orientation and the learning organization. Journal of Marketing, 59.

Thompson, Strickland, Gamble (2007), Crafting and executing a strategy, edition Irwin, McGraw Hill Boston U.S.A. UNIDO (2010).Pharmaceutical sector profile: Kenya. Retrieve from http://www.unido.org/.../Kenya_Pharma\%20Sector\%20profile_TEGL0050

Weihnrich, H. and Kootzn, H. (1993). Management: A Global Perspective (10th Ed.)McGraw Hill. 